Instituto Internacional de Investigación y Desarrollo Tecnológico Educativo INDTEC, C.A.

DOI: https://doi.org/10.29394/Scientific.issn.2542-2987.2020.5.16.13.246-267

OAI-PMH: http://www.indteca.com/ojs/index.php/Revista Scientific/oai

Artículo Original / Original Article

\title{
Ecocidio en México: Conceptualización a través de un Análisis de la Jurisdicción Nacional e Internacional
}

\author{
Autoras: Zaira Ramírez Apud López \\ Benemérita Universidad Autónoma de Puebla, BUAP \\ zaira.ramirezap@correo.buap.mx \\ Puebla, México \\ https://orcid.org/0000-0002-9912-8316 \\ Tammara Ramírez Apud López \\ Benemérita Universidad Autónoma de Puebla, BUAP \\ tammaracurso@gmail.com \\ Puebla, México \\ https://orcid.org/0000-0002-3339-1998
}

\section{Resumen}

En la actualidad las temáticas ambientales han cobrado relevancia ante el planteamiento de los cambios que se han generado en el ambiente, producto de las múltiples actividades antropogénicas. Los diversos reportes y estadísticas de las entidades dedicadas al cuidado y protección del ambiente han sido cruciales para reconocer la existencia de vacíos legales en este ámbito. En México, por la diversidad de sus ecosistemas y su extensión territorial, se reconoce el esfuerzo requerido por parte de todas las instancias oficiales y legales involucradas, sin embargo, en lo ambiental surge un concepto que no se tiene legislado, ni tampoco definido claramente, este término es el Ecocidio. El propósito de esta investigación es realizar un análisis-sintético, para conocer la importancia y amplitud del concepto Ecocidio, así como presentar las lagunas legales que tiene el sistema jurídico en México, en comparación con otros ambientes internacionales. Lo anterior nos permite desarrollar un significado sobre Ecocidio, para tener una conceptualización tentativa de acuerdo a las problemáticas actuales y entender su relevancia en el sistema legal.

Palabras clave: México; jurisdicción internacional; medio ambiente; estadísticas ambientales.

Cómo citar este artículo:

Apud, Z., \& Apud, T. (2020). Ecocidio en México: Conceptualización a través de un Análisis de la Jurisdicción Nacional e Internacional. Revista Scientific, 5(16), 246-267, e-ISSN: 2542-2987. Recuperado de: https://doi.org/10.29394/Scientific.issn.2542-2987.2020.5.16.13.246-267

Fecha de Recepción: 12-09-2019
Fecha de Aceptación:

08-01-2020
Fecha de Publicación: 05-05-2020 
OAl-PMH: http://www.indteca.com/ojs/index.php/Revista_Scientific/oai

Artículo Original / Original Article

\title{
Ecocide in Mexico: Conceptualization through an Analysis of National and International Jurisdiction
}

\begin{abstract}
At present, environmental issues have gained relevance in the face of the changes that have been generated in the environment, as a result of multiple anthropogenic activities. The various reports and statistics of entities dedicated to the care and protection of the environment have been crucial in recognizing the existence of legal gaps in this area. In Mexico, due to the diversity of its ecosystems and its territorial extension, the effort required by all the official and legal instances involved is recognized, however, in environmental issues a concept arises that is not legislated, nor clearly defined, this term is Ecocide. The purpose of this research is to perform a syntheticanalysis, to know the importance and breadth of the Ecocide concept, as well as to present the legal loopholes that the legal system has in Mexico, compared to other international environments. The above allows us to develop a meaning on Ecocide, to have a tentative conceptualization according to current problems and understand its relevance in the legal system.
\end{abstract}

Keywords: Mexico; international jurisdiction; environment; environmental statistics.

How to cite this article:

Apud, Z., \& Apud, T. (2020). Ecocide in Mexico: Conceptualization through an Analysis of National and International Jurisdiction. Revista Scientific, 5(16), 246-267, e-ISSN: 2542-2987. Recovered from: https://doi.org/10.29394/Scientific.issn.2542-2987.2020.5.16.13.246-267

Date Received: 12-09-2019
Date Acceptance:

08-01-2020
Date Publication: 05-05-2020 


\section{Introducción}

En los últimos años hemos sido testigos de impactos ambientales generados a raíz de los modelos económicos imperantes y la falta de un compromiso con el ambiente, derivado en gran parte, del ver rebasadas a las autoridades responsables del cuidado y protección de los hábitats.

Muchas han sido las voces que se preocupan por generar tratados, leyes, normas, etc., que le den protección al único planeta en el que habitamos, cuyo manejo de sus recursos se ha realizado de forma indiscriminada, en ocasiones en ausencia o en complicidad de las instituciones responsables de su cuidado.

El objetivo de este estudio es realizar un análisis para conocer la importancia y amplitud del concepto Ecocidio, así como presentar las lagunas legales que tiene el sistema jurídico en México, en comparación con otros ambientes internacionales, a través de una revisión de éstos y casos en los que ha sido aplicado.

La importancia de definir, categorizar e incorporar el término de Ecocidio en un sistema jurídico, radica en las características propias de un territorio megadiverso, donde la riqueza biológica del país nos lleva por un lado a ser atractivos a grandes inversiones, que buscan la explotación de los recursos al menor costo y por otra parte, se requiere de la capacitación, sensibilización y compromiso por parte de las autoridades conducentes en el cuidado, manejo y sobre todo respeto de la legislación de nuestro país.

Las problemáticas ambientales en la actualidad han permeado el ánimo de la sociedad, quienes con mayor preocupación requerimos una legislación que permita entender las repercusiones legales que puede tener al atentar contra el ambiente. Así mismo, para legislar sobre el Ecocidio se requiere primero conocer cómo lo definen y en posteriormente revisar su aplicación en la legislación de otros países.

Es importante que dentro del presente trabajo se realiza, a través de un 
análisis-sintético, una revisión sobre los países que tienen incluido el concepto de Ecocidio para entender cómo se aplica el concepto en otros contextos y enfatizar la necesidad de su incorporarlo dentro del sistema jurídico y legal en México.

\section{Metodología}

En esta investigación se parte de una metodología, donde se analizan los elementos que permitan comprender la relevancia del Ecocidio en el ámbito legal, teniendo en cuenta las necesidades actuales que como nación se requieren sobre el cuidado del ambiente.

Así mismo, a través del método analítico-sintético, se vinculó el Ecocidio con factores como la revisión del concepto desde el contexto internacional, la importancia de considerar al ambiente como una personalidad jurídica presentando como un caso específico, la Constitución del Ecuador-, así como, la revisión del sistema jurídico y legal de México con relación a la protección del medioambiente, destacando la relevancia de considerar al Ecocidio dentro de la Legislación Mexicana.

A partir de esta investigación, se presentan los resultados del análisis realizado al sistema legal nacional, con la finalidad de incidir en una propuesta conceptual y la incorporación del Ecocidio, como parte de los delitos ambientales en México, después de reconocer la relevancia de la implementación en la legislación de otras naciones.

\section{Resultados}

\subsection{Conceptualización de Ecocidio en México}

La conceptualización de Ecocidio es importante para entender su profundidad, lo que abarca y la importancia que representa para el medio ambiente sus implicaciones legales.

Por lo anterior, se tiene que la Procuraduría Federal de Protección al 
Ambiente y la Secretaría del Medio Ambientes y Recursos Naturales (PROFEPA-SEMARNAT, 2016), mencionan como Ecocidio: "al daño masivo o destrucción ambiental de un territorio determinado, de tal magnitud que ponga en peligro la supervivencia de los habitantes de dicho territorio" (pág. 16); sin embargo, dentro de la construcción de la misma definición, menciona lo que pudiera entenderse como Ecocidio, sin embargo en ningún documento oficial se tiene registro de esta definición, como se analizará en el presente documento.

Por otro lado, la Ley General del Equilibrio Ecológico y la Protección al Ambiente, en su última reforma publicada en el Diario Oficial de la Federación (DOF, 2018a): no incluyen en ninguno de sus apartados una definición de Ecocidio y tampoco contiene penalizaciones por incurrir en dicha actividad (pág. 2-6).

De tal forma que, no establecer un sistema legal y jurídico que permita tipificar el crimen del Ecocidio y resguardar los recursos naturales de la nación, deja al ambiente en una posición vulnerable para la explotación y negocio de compañías nacionales e internacionales que ven al país como una oportunidad de explotación que llevará tarde o temprano a la pérdida de la riqueza biológica.

Para proponer la incorporación del término Ecocidio dentro del sistema legal y jurídico, se presenta un análisis del concepto en diferentes legislaciones y propuestas teóricas para entender su aplicación y características.

El Ecocidio se ha definido en la mayoría de los casos, como la destrucción tanto de flora como de fauna que conlleva a un desastre ecológico, y es por tal razón, que de forma imperante se ha pedido en las cortes internacionales su incorporación, catalogado como Crimen contra la humanidad. 


\subsection{Ecocidio en el contexto Internacional}

De acuerdo a lo expuesto por Higgins (2010): muchos han sido los esfuerzos de la comunidad internacional por darle al Ecocidio un carácter de Crimen contra la humanidad, por la relevancia que el ambiente tiene per se, como es el caso de la Corte Penal Internacional, que en su instrumento constitutivo (Estatuto de Roma) planteó en su momento, considerar al Ecocidio como el Quinto Crimen Contra la Paz, en la Comisión de las Naciones Unidas para el Derecho Internacional (párr. 6); sin embargo, Berbell (2017): menciona que este intento fue suprimido por el veto de presiones internacionales de países como Estados Unidos, Francia, Gran Bretaña y Holanda (párr. 1).

Esta propuesta fue innovadora y surgió como respuesta a la crisis ambiental que se tiene a nivel global, sin embargo, los intereses económicos de naciones altamente desarrolladas fueron más importantes que cuidar el ambiente para no atentar contra la vida.

Señalan Gauger, Rabatel-Fernel, Kulbicki, Short, y Higgins (2012): que una de las principales defensoras del pronunciamiento de una Ley contra el Ecocidio, es la Abogada Jurista y Activista Británica Polly Higgins, quien ha enfocado sus esfuerzos por la incorporación de una Ley, que Penalice la destrucción de los ecosistemas y, por lo tanto, el Ecocidio sea tipificado como Delito Ambiental Internacional (pág. 5).

Sin embargo, hasta el día de hoy los esfuerzos no se han visto reflejados en las Leyes Internacionales, pese a que se observa, que cada vez son más los países que reconocen la relevancia del ambiente y han incorporado el concepto de Ecocidio dentro del sistema legal.

En la actualidad existen algunas naciones alrededor del mundo, que han establecido una Ley contra el Ecocidio, mismas que se enlistan en la tabla 1. 
Instituto Internacional de Investigación y Desarrollo Tecnológico Educativo INDTEC, C.A.

DOI: https://doi.org/10.29394/Scientific.issn.2542-2987.2020.5.16.13.246-267

OAI-PMH: http://www.indteca.com/ojs/index.php/Revista_Scientific/oai

Artículo Original / Original Article

Tabla 1. Países que han incorporado el Ecocidio dentro de su Marco Legal.

\begin{tabular}{|l|l|}
\hline Documento & Artículo \\
\hline Código Criminal de Georgia (1999) & Art. 409 \\
Código Criminal de la República de Armenia (2003) & Art. 394 \\
Código Criminal de Ucrania (2001) & Art. 441 \\
Código Penal de Kazajistán (1997) & Art. 161 \\
Código Criminal de Kirguistán (1997) & Art. 374 \\
Código Penal de la República de Moldova (2002) & Art. 136 \\
Código Criminal de la Federación Rusa (1996) & Art. 358 \\
Código Criminal de Tayikistán (1998) & Art. 400 \\
Código Penal de Vietnam (1990) & Art. 278 \\
\hline
\end{tabular}

Fuente: ECOCIDE LAW (2018).

Aunque en estas naciones se ha incorporado el Ecocidio como crimen contra la Paz y la Humanidad, el considerar que en México no ha sido tipificado como delito, representa un riesgo siempre latente con fundamento en los datos proporcionados por la Comisión Nacional para el Conocimiento y Uso de la Biodiversidad (CONABIO, 2016a), quien menciona:

La mayor parte de la diversidad biológica del mundo se concentra en 17 países considerados como megadiversos, entre los que se encuentran Brasil, Colombia, China, Indonesia y México y quienes en conjunto albergan cerca del 60 al $70 \%$ de las formas de vida del planeta (pág. 3).

Así mismo, la Comisión Nacional para el Conocimiento y Uso de la Biodiversidad (CONABIO, 2016b): reporta que México presenta a nivel mundial, el $2^{\circ}$ lugar en especies de reptiles, el $3^{\circ}$ en mamíferos, el $5^{\circ}$ en flora y anfibios y el $11^{\circ}$ en diversidad de especies de aves, al ser considerado como uno de los ecosistemas megadiversos del planeta, se plantea a la vez, la corresponsabilidad de salvaguardar a las especies, tanto de flora como de fauna, que habitan el territorio nacional (pág. 3).

En nuestro país, se expone una serie de factores que han propiciado hablar de una crisis de civilización y el impacto que ésta tiene en nuestro país, es el mismo Toledo (2015), quién menciona: 
En el país: manantiales, ríos, lagos, minerales, petróleo, gas, paisajes escénicos, alimentos, costas, playas y hasta el aire (parques eólicos) han sido mercantilizados...nueve millones de jóvenes no tienen acceso a empleo o a la escuela. Mientras que del otro lado, la élite política tienen sueldos anuales exorbitantes... (pág. 21).

El Ecocidio en México requiere de ser integrado en el pronunciamiento de una ley porque la megadiversidad del territorio mexicano requiere de protección y cuidado, este tema no puede depender de la buena voluntad de la gente, sino de un sistema legal a nivel federal que se aplique a cualquier persona moral o física para salvaguardar la flora y fauna nacional.

\subsection{Aportes en el contexto ecuatoriano}

En la actualidad, otros países de Latinoamérica han jugado el papel que les corresponde en materia de cuidado ambiental, entre los que se encuentra la Constitución del Ecuador (2008), en el Capítulo Séptimo, Artículo 71, relacionado con los Derechos de la Naturaleza, se menciona que:

La naturaleza o Pacha Mama, donde se reproduce y realiza la vida, tiene derecho a que se respete integralmente su existencia y el mantenimiento y regeneración de sus ciclos vitales, estructura, funciones y procesos evolutivos. Toda persona, comunidad, pueblo o nacionalidad podrá exigir a la autoridad pública el cumplimiento de los derechos de la naturaleza. Para aplicar e interpretar estos derechos se observarán los principios establecidos en la Constitución, en lo que proceda. El Estado incentivará a las personas naturales y jurídicas, y a los colectivos, para que protejan la naturaleza, y promoverá el respeto a todos los elementos que forman un ecosistema. (pág. 11).

Este es un aporte interesante, al plantear en Ecuador a la naturaleza como personalidad jurídica, implica que tiene derechos por constitución, y se pueden ejercer acciones penales en contra de cualquiera que atente contra ésta. 
Otro punto importante en los aportes del Ecuador, que plantea Brunicelli (1995), citado por Macías (2009), para el cuidado del medio ambiente, es el siguiente:

Puede afirmarse que el futuro de la materia [el medio ambiente] se orientará hacía la sistematización normativa interna e internacional del derecho ambiental, a la creación de los correspondientes órganos de tutela, y a la definición de los procedimientos que hagan posible y faciliten la exigibilidad del respeto a tales derechos (pág. 122).

De acuerdo con lo anterior, en primer lugar, se reconoce que el derecho ambiental debe responder a objetivos internacionales, que permitan unir esfuerzos y dar respuesta pronta a crímenes contra la naturaleza.

En segundo lugar, plantea la importancia de la creación y organización de los diferentes comités, instituciones u órganos que vigilen el cumplimiento de la ley. Así mismo, la ciudadanía requiere de estar informada y participar en la formación de comités ciudadanos para involucrarse y tener conciencia sobre la participación en cuidar el medio ambiente.

En el Ecuador se ha trabajado en formar una ciudadanía consciente del cuidado del medio ambiente y de los crímenes contra la naturaleza, esto es lo que se requiere para tener impacto a nivel nacional y dar respuesta a objetivos internacionales.

Para el caso de México, se requiere de una campaña que involucre los medios de comunicación masiva y redes sociales para trabajar en informar y concientizar a la ciudadanía, sobre lo que implica un Ecocidio promoviendo la participación activa para hacer valer los derechos del medio ambiente.

\subsection{Antecedentes Legales de Protección del Ambiente en México}

En nuestro país, ha existido a través del tiempo un interés por proteger el medio ambiente, sin embargo, no se ha planteado en las leyes o en la constitución el término de Ecocidio, para determinar las características y nivel 
de daño ambiental que conduce a violentar los recursos naturales.

Los antecedentes legales respecto al cuidado del medio ambiente inician a partir de la Ley Federal de Caza, publicada en el Diario Oficial de la Federación (1952): en donde se presenta "la conservación, restauración y fomento de la fauna silvestre" (art. 1); a partir de esta fecha se implementaron diversas legislaciones de protección ambiental, como son:

- Para Baqueiro, Baqueiro y Baqueiro (2010): la Ley Federal para Prevenir y Controlar la Contaminación, se publica el primer ordenamiento jurídico de naturaleza ambiental, y se establece la primera autoridad para su aplicación, la Secretaría de Salubridad y Asistencia (pág. 237).

- Según Centro de Estudios Sociales y de Opinión Pública (CESOP, 2006a): el Plan Nacional de Desarrollo en los periodos 1993-1988, fue el primero en incluir el tema ecológico relacionado con factores como el económico y social (párr. 13).

- En el año 1987, el Centro de Estudios Sociales y de Opinión Pública (CESOP, 2006b): explica que se modificaron los Artículos 27 y 73 Constitucional, el primero, faculta al Estado para mantener el equilibrio ecológico. El segundo, faculta al Congreso para legislar en materia de protección ambiental (párr. 14).

- La Procuraduría Federal de Protección al Ambiente (PROFEPA, 2010): expone que el Instituto Nacional de Ecología y la Procuraduría Federal de Protección al Ambiente, es el encargado de la normatividad y criterio ambiental, así como evaluar los manifiestos de impacto ambiental, por su parte, la Procuraduría vigila, inspecciona y verifica el cumplimiento de la normatividad (párr. 11).

Por lo anterior, estas instituciones tienen como tarea principal 
incrementar los niveles de observancia de la normatividad ambiental, a fin de hacer cumplir las leyes en esta materia. Por otra parte, la Secretaría de Medio Ambiente y Recursos Naturales (SEMARNAT, 2018): expone que para complementar el cuidado de los recursos naturales y reforzar su vigilancia se creó en 1994 la Secretaría de Medio Ambiente Recursos Naturales y Pesca, cuya finalidad es planear el manejo de recursos naturales y políticas ambientales desde un punto de vista integral, articulando los objetivos económicos, sociales y ambientales (párr. 4).

Dentro de los antecedentes relacionados con la protección ambiental, otras de las modificaciones que se han generado se presentan a continuación:

- En el artículo 25 de la Constitución Política de los Estados Unidos Mexicanos, publicado en el Diario Oficial de la Federación (DOF, 1999): la Reforma al Artículo $4^{\circ}$ Constitucional, se adiciona el párrafo quinto, donde hace referencia a que "toda persona tiene derecho a un medio ambiente adecuado para su desarrollo y bienestar" (párr. 9).

- La Comisión Nacional de Áreas Naturales Protegidas (CONANP, 2016): se crea en el Marco del Día Mundial del Medio Ambiente, cuyo objetivo es proteger el capital natural de nuestro país (párr. 1).

- En la Ley de la Administración Pública Federal, presentada en el Diario Oficial de la Federación (DOF, 2003): se suprime la Secretaría de Medio Ambiente, Recursos Naturales y Pesca, dando origen a la Secretaría de Medio Ambiente y Recursos Naturales (pág. 9); cuyas funciones están vigentes actualmente.

Estos han sido los esfuerzos de nuestra nación por crear un sistema de protección para los recursos naturales. Se han creado Secretarías y otras han cambiado su ámbito de competencia, sin embargo, sigue quedando de manifiesto que se requiere trabajar en la integración dentro del sistema jurídico 
Instituto Internacional de Investigación y Desarrollo Tecnológico Educativo INDTEC, C.A.

DOI: https://doi.org/10.29394/Scientific.issn.2542-2987.2020.5.16.13.246-267

OAI-PMH: http://www.indteca.com/ojs/index.php/Revista_Scientific/oai

Artículo Original / Original Article

la tipificación del Ecocidio como Crimen contra la Humanidad, lo que permitirá llevar a cabo una verdadera protección de la naturaleza en México considerando que el reconocer el daño ambiental no sólo es resarcir daños, sino involucra la prevención de los mismos.

\subsection{Bases Constitucionales en Materia Ambiental en la Constitución Política de los Estados Unidos Mexicanos (CPEUM)}

La Naturaleza del Derecho Ambiental es todavía una discusión que se mantiene por los estudiosos del Derecho, autores como López y Ferro (2006a): plantean un interesante debate teórico en torno al lugar que debería ocupar, como Ciencia Informativa, Disciplina Académica, Rama del Derecho Público, del Derecho Económico o bien del Derecho Privado (págs. 9-13).

Asimismo, diversos autores han intentado darle una categoría de la "Rama Autónoma del Derecho", por la especificidad de su interés, ya que cumple con los requisitos que según Fraga citado por López y Ferro (2006b), mencionan: “1). Presencia de principios propios; 2). Que existan técnicas jurídicas propias; y 3). Referencia a determinada categoría de personas, de objetos o de relaciones" (pág. 10).

El Derecho Ambiental también, es definido por Andaluz (2006): como el conjunto de normas y principios cuya finalidad es regular la conducta humana y lograr un equilibrio entre hombre- ambiente para tener un ambiente sano y lograr el desarrollo sostenible (pág. 505).

Sea cual fuere la discusión teórica, el principio es claro, salvaguardar al medio ambiente y lograr involucrar al ser humano en su cuidado. Por otra parte, para el cumplimiento de la Ley que ejerce la Constitución Política de los Estados Unidos Mexicanos (CPEUM), existen bases constitucionales, , que se presentan en la tabla 2, de diversos artículos dirigidos hacia el cuidado y protección del ambiente, en los que se resalta el beneficio para la persona y que el Estado debe hacer respetar este derecho. 
Tabla 2. El medio ambiente en la CPEUM.

\begin{tabular}{|l|l|}
\hline Artículo & Derecho \\
\hline $\begin{array}{l}\text { Artículo } 4^{\circ}, \\
\text { párrafo quinto }\end{array}$ & $\begin{array}{l}\text { Establece que "toda persona tiene derecho a un medio } \\
\text { ambiente sano para su desarrollo y bienestar" (pág. 6). }\end{array}$ \\
\hline Artículo $25^{\circ}$ & $\begin{array}{l}\text { Al Estado le corresponde la rectoría del Desarrollo } \\
\text { Nacional... en beneficio..., de los recursos productivos, } \\
\text { cuidando su conservación y el medio ambiente (pág. 20). }\end{array}$ \\
\hline Artículo $27^{\circ}$ & $\begin{array}{l}\text { Establece que la nación regulará el aprovechamiento de los } \\
\text { elementos naturales susceptibles de apropiación... (pág. 21). }\end{array}$ \\
\hline $\begin{array}{l}\text { Artículo } 73^{\circ}, \\
\text { fracción XXIX-G. }\end{array}$ & $\begin{array}{l}\text { Es facultad del Congreso expedir leyes... en materia de } \\
\text { protección al ambiente y de preservación y restauración del } \\
\text { equilibrio ecológico (pág. 53). }\end{array}$ \\
\hline $\begin{array}{l}\text { Artículo } 115^{\circ}, \\
\text { fracción } \mathrm{V} \text { inciso G }\end{array}$ & $\begin{array}{l}\text { Los Estados y Municipios, están facultados para... la } \\
\text { creación y administración de... reservas ecológicas y } \\
\text { aplicación de programas de ordenamiento... (pág. 86). }\end{array}$ \\
\hline $\begin{array}{l}\text { Artículo } 122^{\circ}, \\
\text { inciso C }\end{array}$ & $\begin{array}{l}\text { A la Federación, los Estados y Municipios, “...corresponderá } \\
\text { acordar las acciones... de protección al ambiente..." (págs. } \\
\text { 96-97). }\end{array}$ \\
\hline
\end{tabular}

Fuente: Diario Oficial de la Federación (1917).

Se observa que en cada artículo se establecen diversos aspectos ambientales y las respectivas competencias responsables (Federal, Estatal o Municipal), sin embargo, la Constitución como máximo órgano legal al no considerar el Ecocidio en ninguno de los artículos, presenta la limitante de poder ejercer acción legal para contravenir a quién atente de esta forma al medio ambiente.

\subsection{Delitos Ambientales en la Legislación Mexicana dentro del Código Penal Federal}

Entender qué es un delito ambiental toma relevancia, porque a partir de su definición y ámbitos involucrados, se puede ejercer la ley para la protección al medio ambiente.

Para Gibbs y Boratto (2017): el delito ambiental se desprende de lo que se conoce como un crimen ambiental, y se ha definido como aquel que se comete cuando se altera de forma negativa al medio ambiente y se producen 
Instituto Internacional de Investigación y Desarrollo Tecnológico Educativo INDTEC, C.A.

DOI: $h$ ttps://doi.org/10.29394/Scientific.issn.2542-2987.2020.5.16.13.246-267

OAI-PMH: http://www.indteca.com/ojs/index.php/Revista_Scientific/oai

Artículo Original / Original Article

daños que permanecen en el tiempo (pág. 2); afectando los derechos humanos y constitucionales. Por lo tanto, quien presenta la denuncia contra el delito ambiental es la persona o grupo social ambientalmente afectado.

Señala Carmona (2015): que en México se facultó a la Secretaría del Medio Ambiente y Recursos Naturales, para que cualquier persona pueda presentar una denuncia, excepto en los delitos contra la gestión ambiental, que se persiguen por querella. Sin embargo, los mecanismos para la defensa del Derecho Ambiental en nuestro país, se encuentran en un estado de reestructuración desde el año 1988, cuando entra en vigor la Ley General de Equilibrio Ecológico y Protección al Ambiente (pág. 93).

Por otra parte, en el Diario Oficial de la Federación (DOF, 2018b): se publica el Código Penal Federal, Título Vigésimo Quinto, donde se establecen los Delitos Contra el Ambiente y la Gestión Ambiental, el cual se encuentra dividido en 5 capítulos, cada uno presenta la descripción legal de los delitos ambientales y demás disposiciones aplicables a la materia Código Penal Federal (pág. 118).

Las penas y sanciones establecidas en el Código Penal Federal, publicado en el Diario Oficial de la Federación (DOF, 2018c): van de 1 a 9 años de prisión y de trescientos a tres mil días de multa de acuerdo al delito cometido; según la propia Ley, las sanciones mencionadas, disminuyen a la mitad cuando el... procesado repare o compense voluntariamente el daño al ambiente, antes de que tal obligación le haya sido impuesta por resolución administrativa o sentencia judicial, establecida en los 5 capítulos arriba mencionados del Código Penal Federal (págs. 118-123).

Esta revisión, nos permite detectar que las sanciones no son altas y se pueden reducir por la reparación o compensación del daño que se hace al ambiente. Se resalta, que al carecer del término de Ecocidio en el Código Penal Federal, ni el considerar sus implicaciones; dificulta aplicar sanciones severas que permitan alcanzar mayor protección ambiental. Si dentro de los 
daños ambientales se considerará la tipificación de delito el concepto de Ecocidio, se podría elevar el nivel de penalización dentro de la propia Ley.

En México, la Ley General de Equilibrio Ecológico y Protección al Ambiente, publicada en el Diario Oficial de la Federación (DOF, 1988), emana de las disposiciones constitucionales en materia de lo ambiental, su objetivo es: "garantizar el cumplimiento y la aplicación de esta Ley y de las disposiciones que de ella se deriven, así como para la imposición de las sanciones administrativas y penales que correspondan" (pág. 2). Cabe resaltar, que en ninguno de los apartados hace mención del Ecocidio como delito ambiental.

\section{Conclusiones}

Como se ha analizado a lo largo de esta investigación, el sistema legal de protección al ambiente, sirve como una base sobre la cual se pretende construir una cultura de respeto y cuidado ambiental; como se ha logrado en otros países que han incorporado en su legislación un apartado específico sobre la conservación y preservación del ambiente.

México ha sido pionero en muchas de las iniciativas respecto a la legislación del cuidado ambiental, sin embargo, una gran parte de estas normatividades han quedado envueltas en los aspectos burocráticos, lo que impide el aterrizar en una legislación que se vea reflejada en el actuar, tanto del gobierno, como de los diferentes actores involucrados en el cuidado ambiental.

Constantemente en México se autorizan y realizan obras de infraestructura que conllevan a un cambio de uso de suelo y que no cuentan con un manifiesto de impacto ambiental, como la misma Ley lo indica, lo que provoca que la flora y fauna se vean afectadas, ya sea por sacar adelante proyectos políticos o desarrollos turísticos y empresariales.

A través de este estudio se analizó la importancia de implementar en 
México, no sólo penalizaciones por daños ambientales -las cuales existen-, sino categorizar en un rubro de atención toda aquella actividad que lleve a un desastre ecológico y cuyas repercusiones sean causadas por el hombre, esto se debería considerar como Ecocidio.

La falta de sensibilidad hacia el daño ambiental y una carente cultura en materia jurídica, son temas que al plantearse dentro de las agendas ambientales, pueden servir en el establecimiento de una nueva relación entre las personas y su ambiente, pero hasta que ese día se presente, debemos utilizar todos los mecanismos jurídicos, normativos y legales para resguardar al planeta y lo que en él habita.

De tal forma la propuesta sobre el Concepto de Ecocidio para México, debe considerarse como cualquier daño ambiental que afecte la flora, fauna y los recursos naturales (atmosféricos e hídricos) de un ambiente natural, rural o urbano y donde se logre la tipificación como Crimen contra la Humanidad y el Ambiente.

La propuesta realizada, retoma el aspecto urbano debido a que en ocasiones no se atienden las afectaciones ambientales si no se encuentran en zonas protegidas o naturales. Las zonas urbanas y rurales también requieren de cuidar y generar espacios de cultura hacia el cuidado del ambiente, para su preservación y protección.

Por lo anterior y en tanto se busquen nuevos esquemas de protección ambiental, se propone el establecimiento del Ecocidio como "Crimen contra la Humanidad y el Ambiente", un tema que debe incorporarse en las agendas ambientales no sólo de nuestra nación, sino en el ámbito mundial.

\section{Referencias}

Andaluz, C. (2006). Manual del Derecho Ambiental. Segunda edición. Lima, Perú: Edición Proterra. Recuperado de: https://agua.org.mx/wpcontent/uploads/2017/05/Manual-de-Derecho-Ambiental.pdf 
Baqueiro, E., Baqueiro, L., \& Baqueiro, E. (2010). Introducción al Derecho Ecológico. $2^{\mathrm{a}}$ edición. México: Oxford University Press.

Berbell, C. (2017). El ecocidio fue suprimido del borrador del Estatuto de Roma por presiones de EE.UU., Francia, Gran Bretaña y Holanda. Madrid, España: Confilegal. Recuperado de:

https://confilegal.com/20170715-ecocidio-fue-suprimido-del-borradordel-estatuto-roma-presiones-ee-uu-francia-gran-bretana-holanda/

Carmona, M. (2015). Derechos del Medio Ambiente. Nuestros Derechos. Tercera edición, Colección Biblioteca Constitucional, ISBN: 978-6079276-57-7. México: Universidad Nacional Autónoma de México; Instituto de Investigaciones Jurídicas. Recuperado de:

https://www.inehrm.gob.mx/work/models/Constitucion1917/Resource/1 296/medio ambiente pdf electronico.pdf

CESOP (2006a,b). "Antecedentes”, Medio Ambiente. México: Centro de Estudios Sociales y de Opinión Pública. Recuperado de:

http://archivos.diputados.gob.mx/Centros Estudio/Cesop/Eje tematico 12 mambiente.htm

CONABIO (2016a,b). Desarrollo de Capacidades para el Monitoreo de Bosques en México. México: Comisión Nacional para el Conocimiento y Uso de la Biodiversidad; Impresión: Offset Rebosán, S.A. de C.V. Recuperado de:

https://www.biodiversidad.gob.mx/sistema monitoreo/pdf/brochure sm nb.pdf

CONANP (2016). La CONANP Festeja 16 Años de Vida en el Día Mundial del Medio Ambiente. Comunicado. México: Comisión Nacional de Áreas Naturales Protegidas. Recuperado de:

https://www.gob.mx/conanp/prensa/la-conanp-festeja-16-anos-de-vidaen-el-dia-mundial-del-medio-ambiente-56508

Constitución del Ecuador (2008). Capítulo Séptimo, Artículo 71. Ecuador: 
Instituto Internacional de Investigación y Desarrollo Tecnológico Educativo INDTEC, C.A.

DOI: https://doi.org/10.29394/Scientific.issn.2542-2987.2020.5.16.13.246-267.

OAI-PMH: http://www.indteca.com/ojs/index.php/Revista_Scientific/oai

Artículo Original / Original Article

Publicación Oficial de la Asamblea Constituyente. Recuperado de: http://www.hlrn.org/img/documents/Constitucion del Ecuador 2008.p df

DOF (2018a). Ley General de Equilibrio Ecológico y la Protección al Ambiente. Última Reforma DOF 05-06-2018. México: Diario Oficial de la Federación. Recuperado de:

http://www.diputados.gob.mx/LeyesBiblio/pdf/148 050618.pdf

DOF (2018b,c). Código Penal Federal. Última reforma DOF 29 de enero de 2016. México: Diario Oficial de la Federación. México: Diario Oficial de la Federación. Recuperado de:

https://mexico.justia.com/federales/codigos/codigo-penal-federal/gdoc/ DOF (2003). DECRETO para la creación del Instituto Nacional de Ecología (INE) y la Procuraduría Federal de Protección al Ambiente (PROFEPA). México: Diario Oficial de la Federación. Recuperado de:

http://dof.gob.mx/copias.php?acc=ajaxPaginas\&paginas=9\&seccion=U NICA\&edicion=28172\&ed=MATUTINO\&fecha $=13 / 08 / 2003$

DOF (1999). DECRETO por el que se declara la adición de un párrafo quinto al artículo $4^{\circ}$ constitucional y se reforma el párrafo primero del artículo 25 de la Constitución Política de los Estados Unidos Mexicanos. México: Diario Oficial de la Federación. Recuperado de:

http://www.diputados.gob.mx/LeyesBiblio/ref/dof/CPEUM ref 141 28j un99 ima.pdf

DOF (1988). Ley General del Equilibrio Ecológico y la Protección al Ambiente. Última Reforma DOF 05-06-2018. México: Diario Oficial de la Federación. Recuperado de:

http://www.diputados.gob.mx/LeyesBiblio/ref/lgeepa.htm

DOF (1952). Ley Federal de Caza. Publicado en el DOF. de fecha 5 de enero. México: Poder Ejecutivo Federal. Recuperado de:

http://transparencia.diputados.gob.mx/upload/upload files/ESCFIN F 


\section{0-11-2009 T 1259614922 R 4.pdf}

DOF (1917). Constitución Política de los Estados Unidos Mexicanos. CPEUM. Última reforma DOF 29 de enero de 2016. México: Diario Oficial de la Federación. Recuperado de:

http://www.ordenjuridico.gob.mx/Constitucion/cn16.pdf

ECOCIDE LAW (2018). Leyes de Ecocidio existentes. [Sitio Web]. Estados Unidos: Polly Higgins. Recuperado de:

https://eradicatingecocide.com/es/leyes-de-ecocidio-existentes/

Gauger, A., Rabatel-Fernel, M., Kulbicki, L., Short, D., \& Higgins, P. (2012). The Ecocide Project 'Ecocide is the missing $5^{\text {th }}$ Crime Against Peace'. First published, ISBN: 978-0-9575210-5-6. London, England: Human Rights Consortium. Recovered from: https://sasspace.sas.ac.uk/4830/1/Ecocide research report 19 July 13.pdf

Gibbs, C., \& Boratto, R. (2017). Environmental Crime. USA, EE. UU.: Oxford Research Encyclopedia of Criminology. Recovered from:

https://doi.org/10.1093/acrefore/9780190264079.013.269

Higgins, P. (2010). Ley sobre Ecocidio: Propuesta de Enmienda al Estatuto de Roma. Estados Unidos: Comisión de las Naciones Unidas para el Derecho Internacional. Recuperado de:

http://eradicatingecocide.com/wp-content/uploads/2015/11/ELfactsheet Spanish-11.15.pdf

López, P., \& Ferro, A. (2006a,b). Derecho Ambiental. ISBN: 970-9849-36-0. México: IURE Editores, S.A. de C.V. y los autores respecto a la primera edición de la obra. Recuperado de:

http://www.corteidh.or.cr/tablas/29157.pdf

Macías, L. (2009). El constitucionalismo ambiental en la nueva Constitución de Ecuador. Un reto a la tradición constitucional. luris Dictio. Revista de Derecho, 8(12), 21-30, e-ISSN: 2528-7834. Recuperado de: https://doi.org/10.18272/iu.v8i12.684 
Instituto Internacional de Investigación y Desarrollo Tecnológico Educativo INDTEC, C.A.

DOI: https://doi.org/10.29394/Scientific.issn.2542-2987.2020.5.16.13.246-267

OAI-PMH: http://www.indteca.com/ojs/index.php/Revista_Scientific/oai

Artículo Original / Original Article

PROFEPA-SEMARNAT (2016). Malecón Tajamar, Cancún, Quintana Roo:

Situación Ambiental y Jurídica. México: Procuraduría Federal de

Protección al Ambiente; Secretaría de Medio Ambiente y Recursos

Naturales. Recuperado de:

http://www.profepa.gob.mx/innovaportal/file/7970/1/conferencia de pr

ensa tajamar 28 enero bis 2016 profepa.pdf

PROFEPA (2010). La ley al servicio de la naturaleza. Nuestra Historia.

Tlalpan, México: Procuraduría Federal de Protección al Ambiente.

[Documento en línea]. Recuperado de:

https://moodle2.unid.edu.mx/dts cursos mdl/lic/AET/PE/AM/03/5.pdf

SEMARNAT (2018). Antecedentes. México: Secretaría de Medio Ambiente y

Recursos Naturales. Recuperado de:

http://www.cedrssa.gob.mx/post secretarn-

a de medio ambiente y recursos naturales - -n-semarnat-

n.htm\#home

Toledo, V. (2015). Ecocidio en México. La batalla final es por la vida.

México: Editorial Grijalbo. 


\section{Zaira Ramírez Apud López}

e-mail: zaira.ramirezap@correo.buap.mx

Nacida en Puebla, México, el 17 de septiembre del año

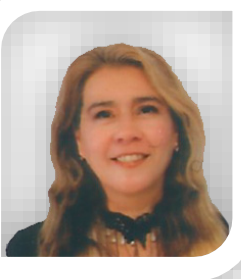
1971. Doctora en Educación para las Ciencias Ingenierías y Tecnologías; Soy Miembro del Sistema Nacional de Investigadores, perteneciente al Padrón de Investigadores de la Benemérita Universidad Autónoma de Puebla (BUAP), México; Consultora Académica para Educación Media Superior en el área de Ciencias Experimentales e Integrante del Comité Científico en Revistas Internacionales; Autora en publicaciones arbitradas, indexadas y capítulos de libros; He sido Directora de la Carrera Educación Básica en la Universalidad Nacional de Educación (UNAE) en Azogues, Ecuador; he ocupado la Jefatura Estatal de Biología en el Colegio de Bachilleres del Estado de Puebla. Ponente en congresos nacionales e internacionales y Directora del Departamento de Tronco Común Universitario para el área de ética en la BUAP. 


\section{Artículo Original / Original Article}

\section{Tammara Ramírez Apud López}

e-mail: tammara.ramirezapud@udlap.mx

Nacida en Mérida, Yucatán, México, el 30 de

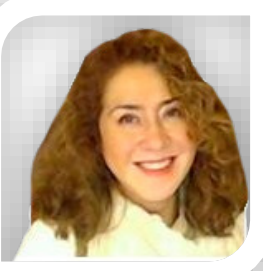
septiembre del año 1968. Doctora en Educación para las Ciencias Ingenierías y Tecnologías; Colaboradora en la Maestría en Educación Media y Básica de la Universidad de las Américas Puebla (UDLAP); Imparto las asignaturas de Desarrollo de Habilidades de Pensamiento Complejo, Formación Humana, Métodos de investigación para las ciencias sociales, Elaboración de reactivos para instrumentos de evaluación y Seminario de tesis en las licenciaturas de Criminología y Derecho de la Facultad de Derecho y Ciencias Sociales; Profesora colaboradora de la Universidad Nacional de Educación (UNAE) en Ecuador; Línea de investigación en Habilidades de pensamiento complejo, procesos educativos para solución de problemas y temas con impacto educativo.

El contenido de este manuscrito se difunde bajo una Licencia de Creative Commons ReconocimientoNoComercial-Compartirlgual 4.0 Internacional 